Synthesis of Natural Products and Drugs

\section{Key Words}

electrocyclization biomimetic

K. A. PARKER, * Y.-H. LIM (STATE UNIVERSITY OF NEW YORK AT STONY BROOK, USA)

The Total Synthesis of (-)-SNF4435 C and (+)-SNF4435 D

J. Am. Chem. Soc. 2004, 126, 15968-15969.

\title{
Total Synthesis of (-)-SNF4435 C and (+)-SNF4435 D
}

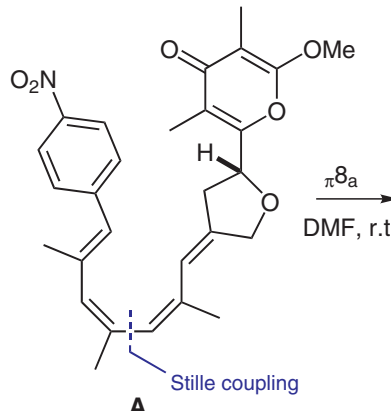

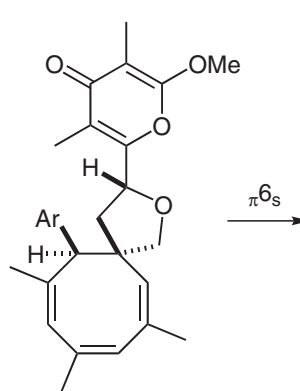

$\pi 6_{\mathrm{S}}$

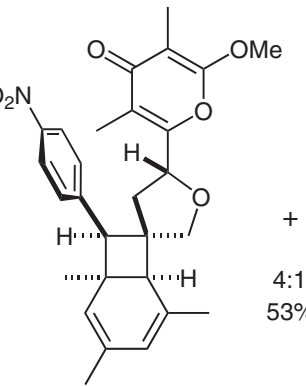

(-)-SNF4435 C

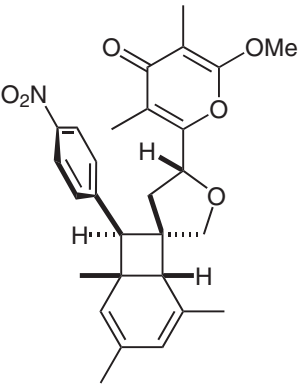

(+)-SNF4435 D
Significance: SNF4435 C and SNF4435 D are metabolites of Streptomyces spectabilis that display immunosuppressant and multidrug resistance reversal activity.
Comment: Parker and Lim adopt a biomimetic approach in which the tetraene $(\mathbf{A})$ undergoes first a conrotatory ${ }_{\pi} 8_{a}$ electrocyclization followed by a disrotatory ${ }_{\pi} 6_{S}$ electrocyclization under the conditions of the Stille coupling (DMF, room temperature) to give a 4:1 mixture of the diastereoisomeric target molecules. The natural products are isolated as a 2.3:1 mixture (see also: J. E. Moses, R. M. Adlington, R. Rodriguez, S. J. Eade and J. E. Baldwin Chem. Commun. 2005, 1687-1689). 